\title{
Cellular and Molecular Evidence of Acetaldehyde Elimination and Intracellular Environment Antioxidation by L-Cysteine
}

\author{
Zhenjing Li, ${ }^{1,2}$ Xiaohong Zhang, ${ }^{1,3}$ Yibin Xue, ${ }^{1,2}$ Jingkai Zhang, ${ }^{1}$ Meiling Li, \\ and Cheng Luo $\mathbb{D}^{1,2}$ \\ ${ }^{1}$ State Key Laboratory of Food Nutrition and Safety, Tianjin University of Science \& Technology, Tianjin 300457, China \\ ${ }^{2}$ Key Laboratory of Food Nutrition and Safety, Ministry of Education, School of Food Engineering and Biotechnology, \\ Tianjin University of Science and Technology, Tianjin 300457, China \\ ${ }^{3}$ China CFAPA Testing Technology Company Limited of Dalian, Dalian 116000, China
}

Correspondence should be addressed to Cheng Luo; luo58@yahoo.com

Received 15 April 2018; Accepted 13 August 2018; Published 24 September 2018

Academic Editor: Fabio Polticelli

Copyright (C) 2018 Zhenjing Li et al. This is an open access article distributed under the Creative Commons Attribution License, which permits unrestricted use, distribution, and reproduction in any medium, provided the original work is properly cited.

\begin{abstract}
Acetaldehyde is a harmful metabolite of smoking and drinking. This study was initially intended to facilitate the understanding of the possible injury mechanism of A549 cells damaged by acetaldehyde and the possible protective mechanism of L-cysteine (LCys) by analyzing the oxidative damage indicators, as well as the changes in cell morphology and gene expression. Results from the dithiodimorpholine nitrobenzoic acid colorimetric determination for glutathione peroxidase (GSH-Px) activity in L-Cys groups were significantly higher $(P<0.01)$ than those in the acetaldehyde group in a dose-dependent manner. The expression of cytochrome $c$ oxidase subunit II (COII) mRNA was significantly reduced compared with the control group $(P<0.01)$ and was noticeably restored in the L-Cys groups. Scanning electronic microscopy observation, DAPI staining, and flow cytometry also indicated that L-Cys could effectively attenuate the oxidative damage to A549 cells caused by acetaldehyde and reduces the rate of apoptosis. In conclusion, the protective effects of L-Cys on A549 cells against oxidative damage by acetaldehyde were dosedependent within the range of $10 \mu \mathrm{mol} / \mathrm{L}$ to $160 \mu \mathrm{mol} / \mathrm{L}$. Acetaldehyde damaged the mitochondria and resulted in the apoptosis of A549 cells by reactive oxygen species (ROS), e.g., free radicals, but L-Cys reversed the release of cytochrome $c$ from the mitochondria, reduced the rate of apoptosis, and protected cells from ROS and oxidative stress.
\end{abstract}

\section{Introduction}

Acetaldehyde in the human body is primarily oxidized and metabolized by alcohol dehydrogenase in the liver. Acetaldehyde can also be increased by the uptake of beer, bread, and fruits containing this metabolite. Acetaldehyde can also be acquired from air or from tobacco smoking. Its low boiling point $\left(20.2^{\circ} \mathrm{C}\right)$ causes acetaldehyde to evaporate easily. The perception limit of acetaldehyde in air ranges from $0.07 \mathrm{mg} / \mathrm{L}$ to $0.25 \mathrm{mg} / \mathrm{L}$, which is within the normal range of concentrations for fruity odor [1]. However, higher concentrations will irritate the eyes, nose, throat, and lungs, resulting in cough and polypnea. The intake of high concentrations of acetaldehyde will make people sick, lose consciousness, contract emphysema, or even die from respiratory and cardiovascular failure [2]. Acetaldehyde has been shown to act on the liver by depressing mitochondrial function, decreasing fatty acid oxidation, enhancing glycogenolysis, and decreasing gluconeogenesis from glycerol during alcohol consumption [3]. Acetaldehyde reacts with DNA to form a variety of adducts that may cause polymerase errors and mutations in critical genes, frequently activating proto-oncogenes while inactivating tumor suppressor genes to result in tumorigenesis or carcinogenesis [4-6]. Moreover, acetaldehyde is also considered as a major cause of alcoholism and alcohol addiction $[7,8]$. Therefore, the effective elimination of acetaldehyde is important not only in preventing cellular toxicity but also in the efficient removal of alcohol [9].

Acetaldehyde can be eliminated from the human body in three ways. The first way is to reduce the generation of acetaldehyde by avoiding alcohol drinking and smoking. The second way is achieved via accelerating the metabolism of 
acetaldehyde, such as by increasing the activity of acetaldehyde dehydrogenase (ALDH) in vivo or the content of ALDH to accelerate the conversion of acetaldehyde to acetic acid. The last way is to enable acetaldehyde to combine with another substance to become nontoxic and then be excreted [9].

The reaction of acetaldehyde with most amino acids generates relatively free and stable imines [10]. In particular, L-cysteine (L-Cys) can react with acetaldehyde to produce 2methylthiazolidine-4-carboxylic acid, which is nontoxic to the human body and can be directly excreted [11]. Therefore, L-Cys can accelerate the consumption of acetaldehyde and effectively detoxify organisms subjected to acetaldehyde. Alternatively, L-Cys can also be converted into 2methylthiazolidine-4-carboxylic acid (MTCA), a stable and nontoxic compound [12]. MTCA conversion has been regarded as a way to eliminate carcinogenic acetaldehyde in the digestion system of humans [13].

Methods used for acetaldehyde depletion by L-Cys have been increasingly recognized by different scientific and industrial communities $[14,15]$. L-Cys, with its capability to chemically neutralize acetaldehyde, reportedly prevented ethanol- and acetaldehyde-induced conditioned place preference in the same strain of rats [16]. L-Cys also has a great affinity with acetaldehyde in air and therefore precipitates acetaldehyde [17]. Other studies have shown that acetaldehyde may possess reinforcing properties and that L-Cys can reduce the need to self-administer acetaldehyde [15]. Previous studies demonstrated that acetaldehyde has a significant damage effect on A549 cells in a concentrationdependent manner and L-Cys could protect A549 cells damaged by acetaldehyde and significantly increased its antioxidant capability $[16,18]$. In the present study, the apoptosis-promoting mechanisms of acetaldehyde and the possible protective mechanism of L-Cys are further investigated.

\section{Materials and Methods}

2.1. Cell Culture. The human non-small-cell lung cancer A549 cell line (received as a gift from the Tianjin Institute of Lung Cancer, Tianjin University of Medicine) was routinely cultured in RPMI 1640 medium (Thermo Fisher Scientific Inc., Beijing, China) supplemented with $10 \%$ fetal bovine serum (FBS, Gibco) and $1 \times$ penicillin/streptomycin $(100 \mathrm{U} / \mathrm{mL} P+0.1 \mathrm{mg} / \mathrm{mL} \cdot \mathrm{S}$, Solarbio, Beijing, China) in a humidified incubator (HERAcell 150i, Thermo fisher, USA) at $37^{\circ} \mathrm{C}$ under $5 \% \mathrm{CO}_{2}$. After growing to $80 \%$ confluence in a T25 tissue culture flask (TPP Biochrom AG, Trasadingen, Switzerland), the cells were plated at a density of $1 \times 10^{6}$ or $8 \times 10^{3}$ cells $/ \mathrm{mL}$ in 6 -well plates (Corning, New York, USA) for the following bioassays.

2.2. Cell Treatment. One control group (cells untreated with acetaldehyle), an acetaldehyde group $(200 \mu \mathrm{mol} / \mathrm{L})$, and three L-Cys groups with high, medium, and low concentrations of L-Cys $(640,160$, and $40 \mu \mathrm{mol} / \mathrm{L})$ were included in the study. Cells in the logarithmic phase were diluted to a unicellular suspension of $6 \times 10^{4}$ cells $/ \mathrm{mL}$ and then inoculated to 6-well plates at $37^{\circ} \mathrm{C}$ under $5 \% \mathrm{CO}_{2}$ for $24 \mathrm{~h}$. When the cellular confluence was $80 \%$, RPMI 1640 medium without FBS was used to extend the culture for $24 \mathrm{~h}$ to maintain synchronization. When the cellular confluence was $90 \%, 640,160$, and $40 \mu \mathrm{mol} / \mathrm{L}$, final concentrations of the L-Cys culture solutions (Solarbio, Beijing, China) were prepared for each L-Cys protection group, whereas the control and acetaldehyde groups continued being cultured after replacing with a fresh culture medium. The culture media of all groups were gathered and discarded after $2 \mathrm{~h}$ and then rinsed by phosphate-buffered saline (PBS, $0.2 \mathrm{M}$, $\mathrm{pH}$ 7.2). The acetaldehyde and L-Cys groups were prepared to the final concentration of $200 \mu \mathrm{mol} / \mathrm{L}$ of acetaldehyde culture medium. In the control group, an equivalent volume of fresh cultured medium was used. The cells were then chosen for further analysis after another $24 \mathrm{~h}$ of incubation. All the experiments were repeated thrice with six duplicate wells.

2.3. Cell Viability by MTT Assay. The cell viabilities of A549 cells treated with acetaldehyde or L-Cys at different concentrations were determined using 3-(4,5-dimethylthiazol2-yl)-2,5-diphenyltetrazoliumbromide (MTT) assay to evaluate the possible cytotoxic effects of acetaldehyde or L-Cys.

For the toxicity analysis of acetaldehyde, the A549 cells were treated with different concentrations of acetaldehyde in 96-well plates for $26 \mathrm{~h}$. For the toxicity analysis of L-Cys, the cells were incubated for $2 \mathrm{~h}$ with different concentrations of L-Cys in 96-well plates, and then $200 \mu \mathrm{mol} / \mathrm{L}$ of acetaldehyde was added for another $24 \mathrm{~h}$ of culture.

Aliquots of $20 \mu \mathrm{L}$ of $5 \mathrm{mg} / \mathrm{mL}$ MTT (Solarbio, Beijing, China) in PBS were added to each well in the 96-well plate. The plates were incubated for another $4 \mathrm{~h}$ and then centrifuged. The culture medium was then discarded. The plates were carefully washed twice with PBS buffer. Aliquots of $150 \mu \mathrm{L}$ of dimethyl sulfoxide (DMSO, Amresco, USA) were added to each well and oscillated for $30 \mathrm{~min}$ to extract the insoluble formazan that formed. The absorbance was measured at $570 \mathrm{~nm}$ on a plate reader (ELISA reader, ASYS Hitech, GmbH, Austria).

2.4. Intracellular Activity of GSH-Px. A549 cells were treated with acetaldehyde and L-Cys in a 24-well plate according to the method in the MTT assay. The cells were collected after $24 \mathrm{~h}$, disrupted by ultrasound (Kunshan ultrasonic cleaning machine, $200 \mathrm{w}$ ) in $300 \mu \mathrm{L}$ of PBS for $30 \mathrm{~s}$, and centrifuged at $12,000 \mathrm{r} / \mathrm{min}$ at $4^{\circ} \mathrm{C}$ for $15 \mathrm{~min}$. The supernatant was collected. A Glutathione peroxidase (GSH-Px) kit (Nanjing Jiancheng Bioengineering Institute, Nanjing, China) was used to detect the total protein concentration and GSH-Px activity. The experiment was repeated thrice.

2.5. Expression of COII $m R N A$ by PCR. Approximately 2 million A549 cells were harvested after cultivation. Total RNA was extracted using the RNeasy Mini-Kit (Qiagen RNeasy Mini Kit, Germany) according to the manufacturer 
protocol. RNA integrity was evaluated through electrophoresis in $1.2 \%$ agarose gel. Nondegraded total RNA was displayed as $28 \mathrm{~S}$ and $18 \mathrm{~S}$ bands. First-strand cDNA was synthesized using the PrimeScript 1st Strand cDNA Synthesis kit (Fermentas First Strand cDNA Synthesis Kit, Fermentas) with the Oligo dT-Adaptor primer. PCR amplification was performed using gene-specific PCR primers. The primer sequences were designed by Invitrogen Trading (Shanghai, China) according to their mRNA sequences in the gene bank (accession number of COII: MH378688.1). The sequences of gene-specific PCR primers, the appropriate annealing temperature, and the length of production are summarized in Table 1. The amplification was performed in $20 \mu \mathrm{L}$ reactions, which contained $2 \mu \mathrm{L}$ of $\mathrm{cDNA}, 1 \mu \mathrm{L}$ each of forward and reverse primers, $10 \mu \mathrm{L}$ of PCR $2 \times$ buffer with $\mathrm{MgCl}_{2}, 10 \mathrm{mM}$ of dNTP mixture, $2.5 \mathrm{U}$ Taq polymerase, and $7 \mu \mathrm{L}$ of sterile $\mathrm{ddH}_{2} \mathrm{O}$. Thermal cycling was performed under the following conditions: initial activation at $94^{\circ} \mathrm{C}$ for $180 \mathrm{~s}$, followed by 35 cycles of denaturation at $94^{\circ} \mathrm{C}$ for $30 \mathrm{~s}$, annealing at $58^{\circ} \mathrm{C}$ for $30 \mathrm{~s}$, and an extension at $72^{\circ} \mathrm{C}$ for $45 \mathrm{~s}$. Mouse $\beta$-actin was used as an external standard. A $5 \mu \mathrm{L}$ portion of the RT-PCR product, added with $1 \mu \mathrm{L}$ sample loading buffer, underwent electrophoresis in 1.5\% of agarose gel $(121 \mathrm{~V}, 25 \mathrm{~min})$. Later, electrophoretic bands were scanned for optical density (OD) using a gel scanner (BIORAD Gel Doc XR). The bands were photographed, and the OD was analyzed. The grey density value of each amplified band was recorded, and the ratio of the OD value of each targeted amplified segment and that of the corresponding internal control $\beta$ amplified segment was taken as the semiquantitative indicator of cytochrome $c$ oxidase subunit II (COII) mRNA.

2.6. Cell Morphology Observation. Morphological changes of the cells were tracked using inverted microscopy (AMG EVOS), scanning electron microscopy (Hitachi, Tokyo, Japan), and fluorescence microscopy (GE Healthcare UK Ltd., Buckinghamshire, UK) in this study. For inverted and scanning electron microscopy test, A549 cells $(1 \times 106$ cells $/ \mathrm{mL}$ ) were grown on cover slips in 6-well plates and were treated with L-Cys at different concentrations. The cells were then observed directly. For fluorescence microscopy test, A549 Cells were firstly seeded onto 6-well plates and cultured to adhere overnight. After $48 \mathrm{~h}$ of treatment with L-Cys, the cells were washed with PBS and stained with $2 \mu \mathrm{g} / \mathrm{mL}$ DAPI for $15 \mathrm{~min}$. Images were then captured using the IN Cell analyzer 1000 (GE Healthcare UK Ltd., Buckinghamshire, UK). Each image shown is representative of 20 randomly observed fields.

2.7. Apoptosis Rates and Cell Cycles by Flow Cytometry. A549 cells $\left(1 \times 10^{6}\right.$ cells $\left./ \mathrm{mL}\right)$ were grown on cover slips in 6well plates. The cells were grouped and treated with acetaldehyde, L-Cys, and a combination of acetaldehyde and L-Cys. The cells were then washed in PBS, collected through trypsinization, fixed in 70\% glacial ethanol, washed in PBS, resuspended in $1 \mathrm{~mL}$ of PBS containing $50 \mathrm{U} / \mathrm{mL}$ RNase and
$50 \mu \mathrm{g} / \mathrm{mL}$ propidium iodide (PI), and then incubated for $40 \mathrm{~min}$ in the dark at $4^{\circ} \mathrm{C}$. Cell cycle analysis was performed through flow cytometry (BD, Franklin Lakes, NJ, USA), and the population of cells in each phase was calculated using the ModFit LT software program. Each experiment was conducted thrice.

2.8. Statistical Analysis. Each experiment was repeated at least thrice. Numerical data are presented as mean \pm SE. The difference between means was analyzed using one-way ANOVA, and LSD was used for multiple comparisons. All statistical analyses were performed using SPSS 17.0 software (SPSS, Chicago, IL, USA).

\section{Results}

3.1. Influence of Acetaldehyde and L-Cys on Cell Viabilities of A549 Cells. The cell viability of A549 cells decreased within the range of $0 \mu \mathrm{mol} / \mathrm{L}$ to $900 \mu \mathrm{mol} / \mathrm{L}$ of acetaldehyde (Figure 1(a)) in a dose-dependent manner, which indicates that acetaldehyde can inhibit cell proliferation. Results from Figure 1(b) suggest that L-Cys could protect cells from acetaldehyde-mediated damage in a concentrationdependent manner. Compared with the control group with acetaldehyde treated only, cell viability exhibited a statistically significant difference at the L-Cys concentrations of 40,80 , and $160 \mathrm{~mol} / \mathrm{L}(P<0.01)$. When the L-Cys concentration was greater than $160 \mathrm{~mol} / \mathrm{L}(320,640 \mathrm{~mol} / \mathrm{L})$, cell viability decreased; however, it is still statistically significant higher than the control group with acetaldehyde treated only $(P<0.01)$ (Figure 1(b)).

3.2. L-Cys Influences GSH-Px Activity in A549 Cell Damaged by Acetaldehyde. Similar to cell viability, the intracellular enzyme activity of GSH-Px was decreased with the increment of acetaldehyde concentration (Figure 2(a)), while pretreating cells with L-Cys could obviously weaken the acetaldehydemediated damage, and the effects were dose-dependent (Figure 2(b)). For example, GSP-Px activity was significantly lower than that of the non-acetaldehyde-treated control group when acetaldehyde concentration was up to $50 \mu \mathrm{mol} / \mathrm{L}$ $(P<0.05)$; pretreating cell with $40 \mu \mathrm{mol} / \mathrm{L}$ L-Cys significantly increased the GSH-Px activity when comparing with the group treated with $200 \mu \mathrm{mol} / \mathrm{L}$ acetaldehyde $(P<0.01)$.

\subsection{Influence of L-Cys Treatment on COII mRNA Expression} Damaged by Acetaldehyde. To uncover the possible mechanism of acetaldehyde-induced damage and L-Cys protection of A549 cells, COII mRNA was detected using RT-PCR. Electrophoretogram of RNA and influence of L-Cys on the COII mRNA expression of the A549 cells damaged by acetaldehyde are shown in Figures 3(a), 3(b), and $3(\mathrm{c})$, respectively. The expression of mitochondrial COII mRNA was significantly reduced compared with the control group and was noticeably restored in the L-Cys groups. This finding clearly showed that the oxidative stress of A549 cells mediated by acetaldehyde could 
TABLE 1: Summary of the gene-specific PCR primer sequences, the length of amplificated product, the appropriate annealing temperature used in the experiments, and the number of the amplification cycles.

\begin{tabular}{lccccc}
\hline Gene & Sense primer $\left(5^{\prime} \longrightarrow 3^{\prime}\right)$ & Antisense primer $\left(5^{\prime} \longrightarrow 3^{\prime}\right)$ & Product size & $T_{\mathrm{m}}$ & Cycles \\
\hline$\beta$-Actin & AAATCTGGCACCACACCTT & AGCACTGTGTTGGCGTAGAG & $646 \mathrm{bp}$ & $58^{\circ} \mathrm{C}$ & 35 \\
COII & ATCTTAATGGCACATGCAGC & AGATCTCGGGTGACATTTCGA & $726 \mathrm{bp}$ & $58^{\circ} \mathrm{C}$ & 35 \\
\hline
\end{tabular}

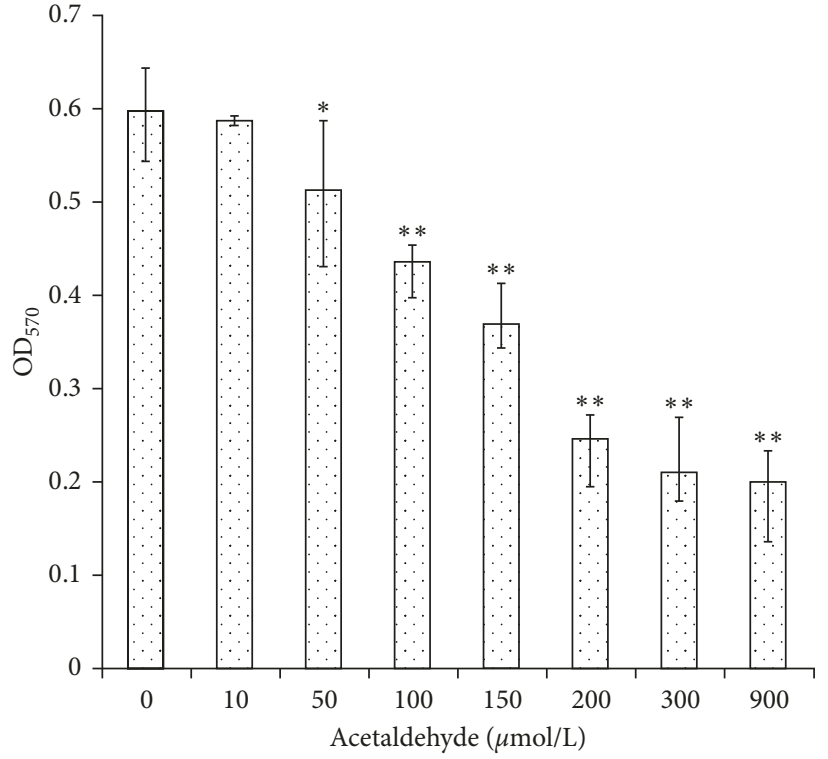

(a)

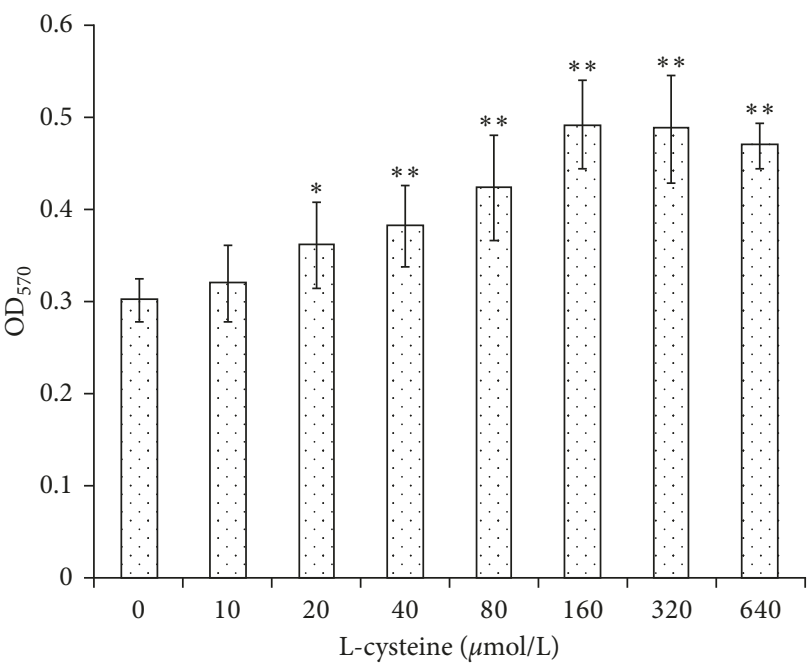

(b)

Figure 1: Cell viability of A549 cells influenced by acetaldehyde (a) and influence of L-Cys on cell viability of A549 cells damaged by $200 \mu \mathrm{mol} / \mathrm{L}$ acetaldehyde (b). Data are represented as the mean \pm S.E. $n=6-12 ;{ }^{*} P<0.05$ and ${ }^{* *} P<0.01$ with respect to the control group.

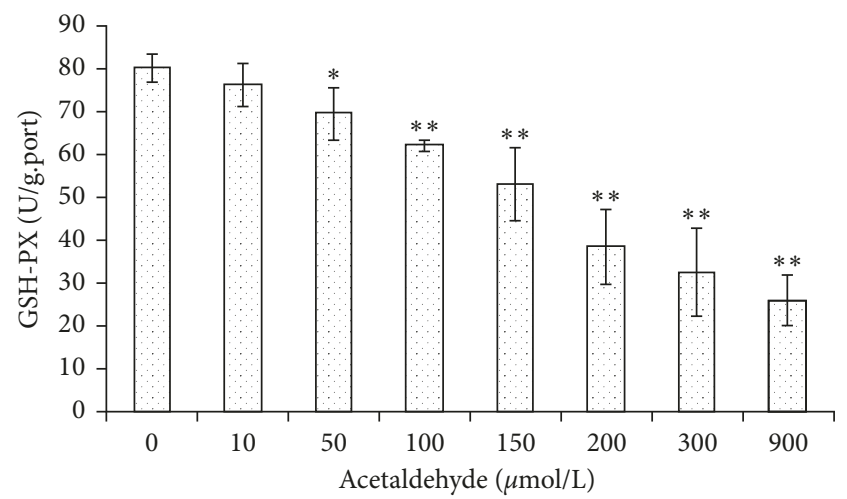

(a)

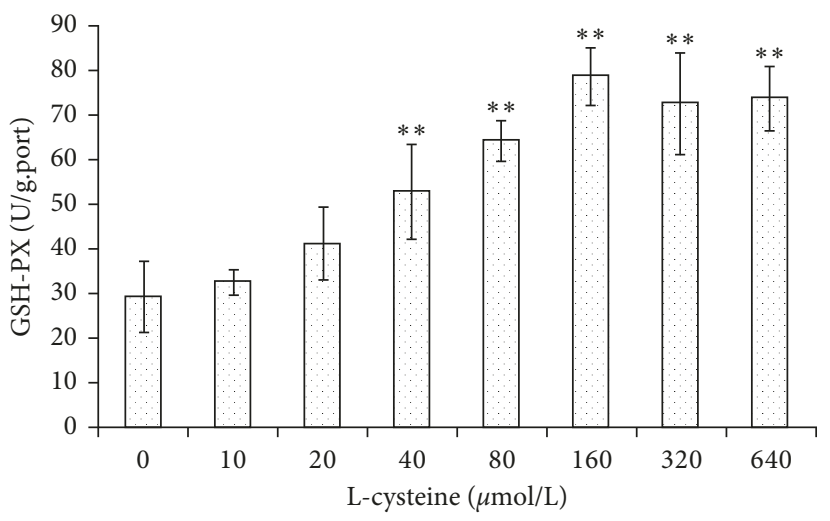

(b)

FiguRE 2: GSH-Px activity of A549 cells influenced by acetaldehyde (a) and influence of L-Cys on the GSH-Px activity of A549 cells damaged by $200 \mu \mathrm{mol} / \mathrm{L}$ acetaldehyde (b). Data are represented as the mean \pm S.E. $n=6-12$; ${ }^{*} P<0.05$ and ${ }^{* *} P<0.01$ with respect to the related control group.

reduce COII expression, which was probably related to DNA damage of mitochondrion. Compared with the $200 \mu \mathrm{mol} / \mathrm{L}$ acetaldehyde group, a low concentration of L-Cys $(40 \mu \mathrm{mol} / \mathrm{L})$ increased the expression of COII mRNA $(P<0.05)$, whereas middle $(160 \mu \mathrm{mol} / \mathrm{L})$ and high concentrations $(640 \mu \mathrm{mol} / \mathrm{L})$ of L-Cys resulted in significantly higher expression $(P<0.01)$, which indicates the protective effect of L-Cys on A549 cells damaged by acetaldehyde (Figures 3(b) and 3(c)).

3.4. Cellular Morphology. Intact A549 cells of the control group were of sharp fusiform or polygonal shape (Figure 4(a)). Cellular density was significantly reduced, and cellular 


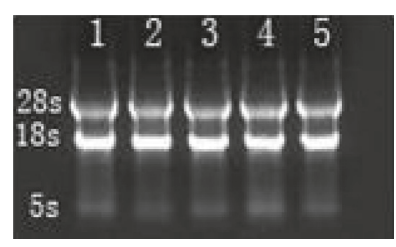

(a)

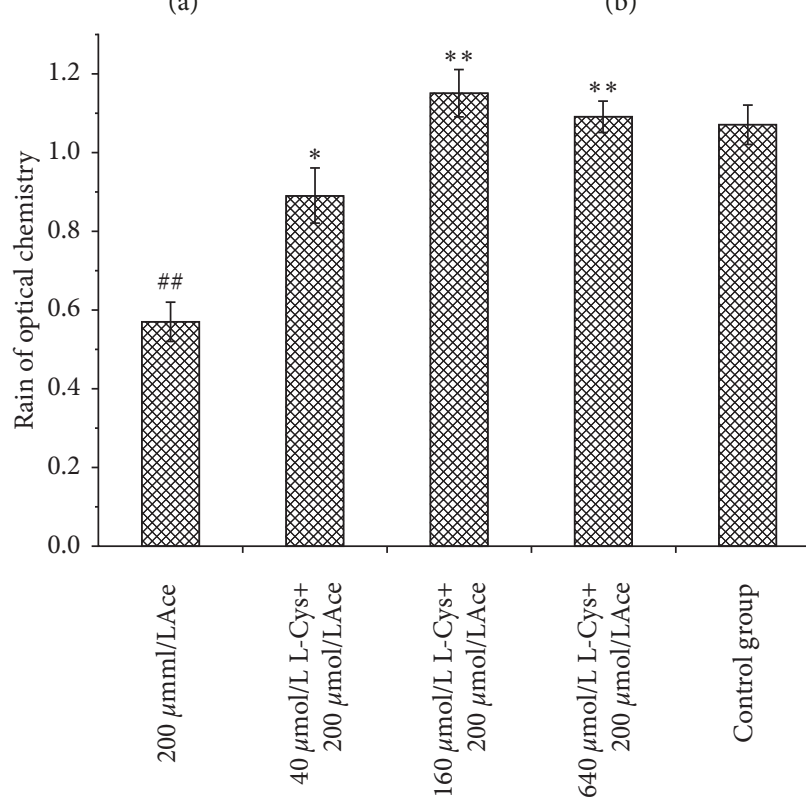

(c)

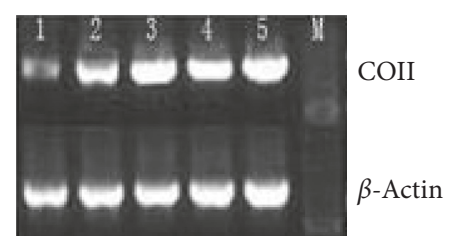

(b)

(c)

FIGURE 3: Electrophoretogram of RNA (a) and influence of L-Cys on the COII mRNA expression of the A549 cells damaged by acetaldehyde (b, c). Lanes 1 to 5 represent $200 \mu \mathrm{mol} / \mathrm{L}$ acetaldehyde, $40 \mu \mathrm{mol} / \mathrm{L} \mathrm{L}-\mathrm{Cys}+200 \mu \mathrm{mol} / \mathrm{L}$ acetaldehyde, $160 \mu \mathrm{mol} / \mathrm{L} \mathrm{L}-\mathrm{Cys}+200 \mu \mathrm{mol} / \mathrm{L}$ acetaldehyde, $640 \mu \mathrm{mol} / \mathrm{L} \mathrm{L}-C y s+200 \mu \mathrm{mol} / \mathrm{L}$ acetaldehyde, and $0 \mu \mathrm{mol} / \mathrm{L} \mathrm{L}-\mathrm{Cys}+0 \mu \mathrm{mol} / \mathrm{L}$ acetaldehyde (control group), respectively. Data are presented as the mean \pm S.E. $n=6-12$; ${ }^{\# \#} P<0.01$, with respect to the control group; ${ }^{*} P<0.05$ and ${ }^{* *} P<0.01$ with respect to the $200 \mu \mathrm{mol} / \mathrm{L}$ acetaldehyde group.

morphology became blurred after being treated by $200 \mu \mathrm{mol} / \mathrm{L}$ acetaldehyde (Figure 4(b)). L-Cys improved the cell morphology at low (Figure 4(c)), medium (Figure $4(\mathrm{~d})$ ), and high concentrations (Figure 4(e)).

The control group under SEM had clear cellular contour and smooth surfaces with microvilli (Figure 4(f)). Under $200 \mu \mathrm{mol} / \mathrm{L}$ acetaldehyde, the microvilli on the cellular surface disappeared and exhibited a blurred contour, an uneven surface, visible tooth-like projections, and cellular crenation (Figure 4(g)). Low, medium, and high L-Cys concentration groups had significantly improved cellular edges or surfaces and overall morphology when compared with the acetaldehyde group (Figures $4(\mathrm{~h}), 4(\mathrm{i})$, and $4(\mathrm{j})$ ). This finding reveals that L-Cys had a protective effect on cells damaged by acetaldehyde.

A living cell nucleus generally has evenly dispersed blue fluorescence under fluorescence microscopy, whereas cell nuclei nuclear apoptosis has dense and massive fluorescence stained particles, and blue fluorescence is brighter than that of normal cells. In apoptotic cells, numerous fluorescent scattered DNA fragments are also seen. As indicated by Figures 4(k) to 4(o), A549 cells in the control group have evenly dispersed blue fluorescence under fluorescence microscopy (Figure 4(k)). After being treated with $200 \mu \mathrm{mol} / \mathrm{L}$ acetaldehyde, apoptotic cells exhibit morphological changes, such as nuclear fragmentation and pyknosis. Nuclear fragmentation, pyknosis, and other apoptotic manifestations are significantly reduced in low, medium, and high L-Cys concentration groups. The medium concentration group has shown a protective effect, which demonstrates that acetaldehyde could induce cellular apoptosis, whereas L-Cys protected cells to some degree (Figures 4(m), 4(n), and 4(o)).

3.5. Apoptosis of A549 Cells by Flow Cytometry. A549 cells with the same treatment were detected through PI single nucleus staining for flow cytometry to analyze cell counts in the different cell cycle phases and in apoptosis. As shown in Figure 5, the cells of the acetaldehyde group in the G1 phase increased from $77.14 \%$ to $82.43 \%$, whereas those in the S phase decreased from $16.56 \%$ to $11.32 \%$ compared with the control group. This finding shows that acetaldehyde can block cells in the G1 phase from proceeding to the S phase, thus inhibiting cellular growth. Compared with the acetaldehyde group, low, medium, and high L-Cys concentration groups have significantly reduced percentages of cells in the G1 phase and increased the proportions of cells in the S phase. Therefore, L-Cys can protect cells from damage caused by acetaldehyde. The cells in the hypodiploid phase before G1 (Sub-G1) were 

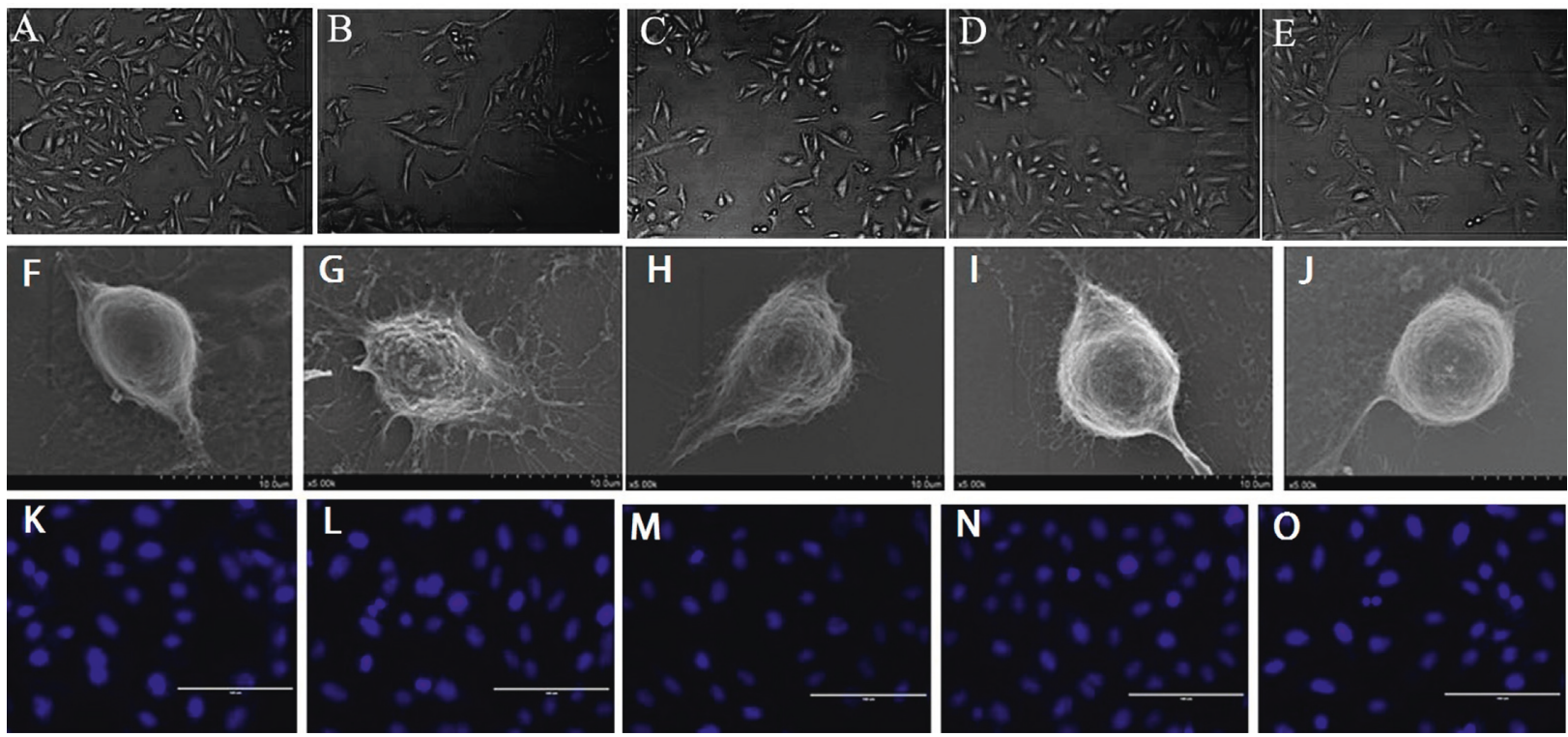

FiguRE 4: Observation of A549 cell morphology under inverted biological microscope $(\times 100)$, scanning electron microscope $(\times 5000)$, and fluorescence microscope (×400). (a, f, k) Control; (b, g, l) $200 \mu \mathrm{mol} / \mathrm{L}$ acetaldehyde; (c, h, m) $40 \mu \mathrm{mol} / \mathrm{L}$ L-Cys $+200 \mu \mathrm{mol} / \mathrm{L}$ acetaldehyde; (d, i, n) $160 \mu \mathrm{mol} / \mathrm{L} \mathrm{L-Cys}+200 \mu \mathrm{mol} / \mathrm{L}$ acetaldehyde; (e, j, o) $640 \mu \mathrm{mol} / \mathrm{L} \mathrm{L}-\mathrm{Cys}+200 \mu \mathrm{mol} / \mathrm{L}$ acetaldehyde.

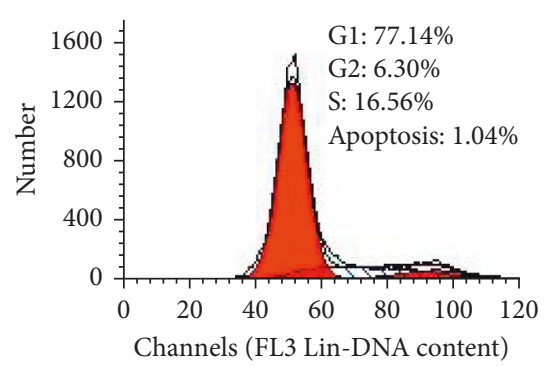

(a)

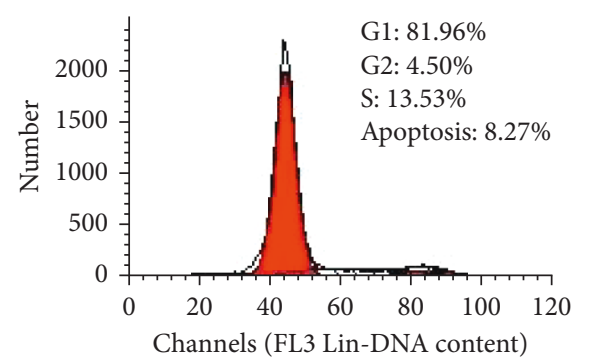

(c)

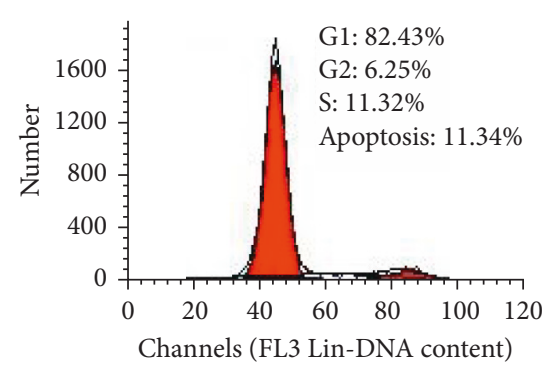

(b)

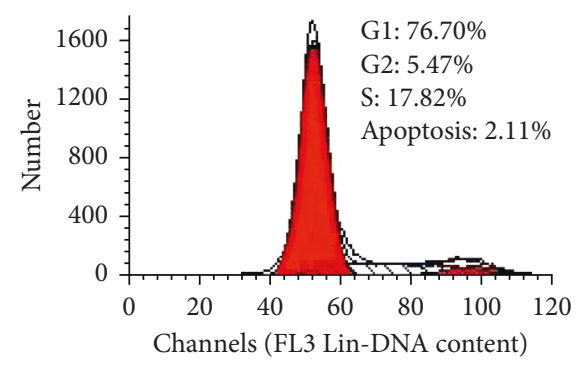

(d)

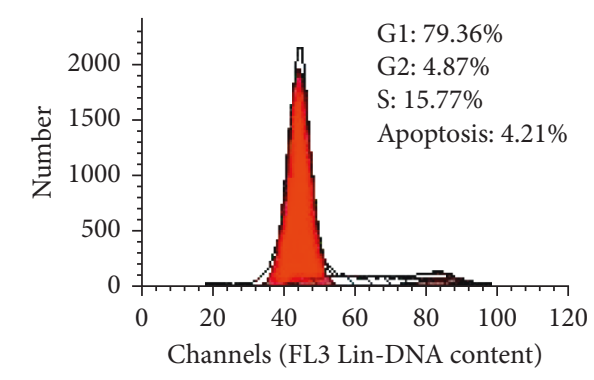

(e)

FIGURE 5: Influence of L-Cys on cell cycle and the apoptosis rate of A549 cell damaged by acetaldehyde. (a) Control; (b) 200 $\mu$ mol/L acetaldehyde; (c) $40 \mu \mathrm{mol} / \mathrm{L}$ L-Cys + acetaldehyde; (d) $160 \mu \mathrm{mol} / \mathrm{L}$ L-Cys + acetaldehyde; (e) $640 \mu \mathrm{mol} / \mathrm{L}$ L-Cys + acetaldehyde. 


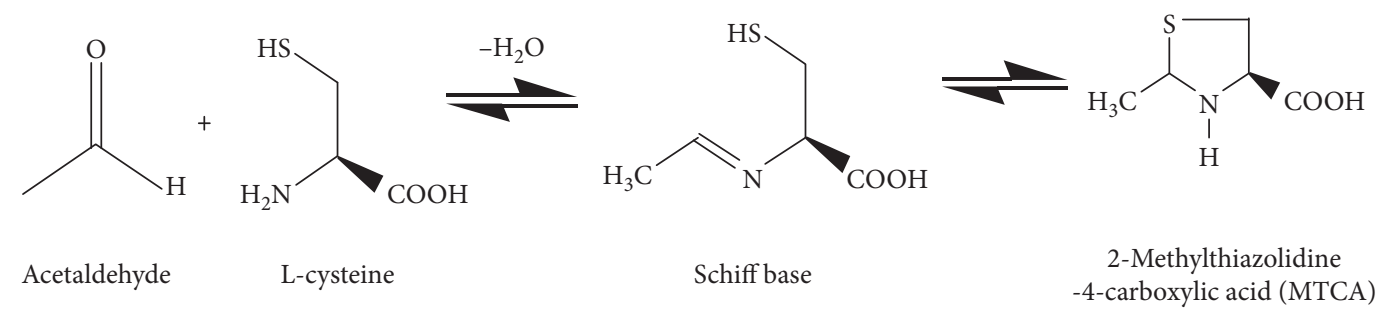

FIGURE 6: Chemical structural formula of L-Cys reacts with acetaldehyde to generate 2-methylthiazolidine-4-carboxylic acid (MTCA).

identified to be apoptotic cells. Results show that the number of cellular apoptosis in the control group was small, whereas the apoptotic rate of the cells in the acetaldehyde group increased from $1.04 \%$ to $11.34 \%$ (Figure 5(b)). The number of cellular apoptosis in the L-Cys groups declined the most with the medium L-Cys concentration group.

\section{Discussion}

Reactive oxygen species (ROS) are constantly produced and eliminated from various cells as products of metabolism. Organisms can normally regulate ROS to control cell apoptosis and proliferation $[19,20]$. At low physiological levels, ROS function as "redox messengers" in intracellular signaling and regulation, whereas excess ROS induce the oxidative modification of cellular macromolecules, inhibit protein function, and promote cell death [21]. Cell growth by ROS and their role as a messenger in various signaling pathways is tightly regulated because once the amount of cellular ROS dramatically changes, the variation of cellular activity may be predicted $[19,21]$.

ROS are largely generated in the mitochondria. Bare mitochondrial DNA (mtDNA) is prone to attacks from free oxygen radicals. Consequently, structure and function can be decayed, which is why mitochondrial damage is always found in different degenerative chronic diseases [22, 23]. COII is the cytochrome $c$ active center coded by mtDNA, and its structural and functional changes leading to damage of the mitochondrial respiratory chain are connected to the release of cytochrome $c$ [24]. The expression of COII mRNA suggests that $200 \mu \mathrm{mol} / \mathrm{L}$ acetaldehyde can significantly reduce the expression of cellular COII mRNA. Two possible pathways exist relative to the damage to mitochondrial COII: one is to cause the COII structure to change and release cytochrome $c$ to increase the oxidative damage of the mitochondrion and cause cells to continue apoptosis, and the other is to cause oxidative damage to mitochondrial DNA to reduce the expression of cytochrome oxidase.

L-Cys reacts with acetaldehyde to generate imine (Figure 6), which is harmless to the human body and can be directly excreted, making L-Cys protective to organisms $[20,25]$. This research demonstrates that L-Cys significantly improves LDH activity, MDA contents, and other antioxidant indexes in acetaldehyde-damaging cells and significantly decreased the apoptosis rate [16]. In this article, we found that the gene expression of COII mRNA in low, medium, and high L-Cys concentration groups significantly increased compared with that of the $200 \mu \mathrm{mol} / \mathrm{L}$ acetaldehyde group. Thus, L-Cys is significantly protective to acetaldehyde-damaging cells.

Acetaldehyde, as an external and intracellular oxidant, can cause direct oxidative damage to biological macromolecules [26, 27]. Smoking, alcoholism, and air pollution increases the level of acetaldehyde in the human body. If a large amount of acetaldehyde produced in vivo cannot be removed promptly, the dynamic pro-oxidative system and antioxidant system of the organism lose balance, such that tissue or cells are frequently oxidatively damaged [28, 29]. Alcohol in the liver is rapidly metabolized into acetaldehyde, and acetate is the main source for carbon systemic circulation. So, there is no toxic effect if the metabolism functions normally. However, in the case of large consumption of alcohol, not only acetaldehyde can be accumulated but also acrolein through oxidation of lipid can be increased in liver. The acrolein has been recently regarded as a pathogenic mediator for many liver diseases [30]. Our results indicate that acetaldehyde can induce cellular damage, reduce GSHPx activity, and cause apoptosis, whereas L-Cys increases GSH-Px activity. Combined with previous research results, we conclude that L-Cys is a powerful protective compound against the oxidative damage induced by acetaldehyde, which is possibly achieved by increasing the antioxidant environment in cells.

\section{Data Availability}

The data used to support the findings of this study are available from the corresponding author upon request.

\section{Conflicts of Interest}

The authors declare that there are no conflicts of interest regarding the publication of this paper.

\section{Authors' Contributions}

Zhenjing Li and Xiaohong Zhang have equally contributed to this work.

\section{Acknowledgments}

This project was supported by an initial funding from the Tianjin city government for "1000 talents plan" program to C. L. 


\section{References}

[1] W. Summer, "Odour Pollution of Air Causes and Control," in Chemical and Process Engineering Series, Leonard Hill, London, UK, 1971.

[2] M. J. Ellenhorn, Ellenhorn's Medical Toxicology: Diagnosis and Treatment of Human Poisoning, Williams and Wilkins, Baltimore, MD, USA, 2nd edition, 1997.

[3] E. L. William, "Acetaldehyde," Journal of Chemical Health and Safety, vol. 16, no. 5, pp. 43-44, 2009.

[4] K. Hori, S. Miyamoto, Y. Yukawa, M. Muto, T. Chiba, and T. Matsuda, "Stability of acetaldehyde-derived DNA adduct in vitro," Biochemical and Biophysical Research Communications, vol. 423, no. 4, pp. 642-646, 2012.

[5] H. S. Yu, T. Oyama, T. Isse et al., "Formation of acetaldehydederived DNA adducts due to alcohol exposure," ChemicoBiological Interaction, vol. 188, no. 3, pp. 367-375, 2010.

[6] C. J. Eriksson, "The role of acetaldehyde in the actions of alcohol (update 2000)," Alcoholism Clinical Experimental Research, vol. 25, no. 1, pp. 15S-32S, 2010.

[7] X. S. Deng and R. A. Deitrich, "Putative role of brain acetaldehyde in ethanol addiction," Current Drug Abuse Reviewse, vol. 1, no. 1, pp. 3-8, 2008.

[8] L. Tampier and M. E. Quintanilla, "Effect of acetaldehyde on acute tolerance and ethanol consumption in drinker and nondrinker rats," Journal of Studies on Alcohol, vol. 63, no. 3, pp. 257-262, 2002.

[9] A. I. Cederbaum, "Alcohol metabolism," Clinics in Liver Disease, vol. 16, no. 4, pp. 667-685, 2012.

[10] F. A. Carey and R. J. Sundberg, Advanced Organic Chemistry Part A: Structure and Mechanisms, Springer, Heidelberg, Germany, 2007.

[11] H. T. Nagasawa, D. J. Goon, W. P. vMuldoon, and R. T. Zera, "2-Substituted thiazolidine-4(R)-carboxylic acids as prodrugs of L-cysteine. Protection of mice against acetaminophen hepatotoxicity," Journal of Medicinal Chemistry, vol. 27, no. 5, pp. 591-596, 1984.

[12] A. Kartal, J. Hietala, I. Laakso et al., "Formulation and in-vivo evaluation of L-cysteine chewing gums for binding carcinogenic acetaldehyde in the saliva during smoking," Journal of Pharmacy and Pharmacology, vol. 59, no. 10, pp. 1353-1358, 2007.

[13] A. Kartal-Hodzic, T. Marvola, M. Schmitt, K. Harju, M. Peltoniemi, and M. Sivén, "Permeability and toxicity characteristics of L-cysteine and 2-methyl-thiazolidine-4carboxylic acid in Caco-2 cells," Pharmaceutical Development and Technology, vol. 18, no. 6, pp. 1288-1293, 2013.

[14] V. Salaspuro, J. Hietala, P. Kaihovaara, L. Pihlajarinne, M. Marvola, and M. Salaspuro, "Removal of acetaldehyde from saliva by a slow-release buccal tablet of L-cysteine," International Journal of Cancer, vol. 97, no. 3, pp. 361-364, 2002.

[15] A. T. Peana, G. Muggironi, G. R. Fois, M. Zinellu, D. Sirca, and M. Diana, "Effect of (L)-cysteine on acetaldehyde selfadministration," Alcohol, vol. 46, no. 5, pp. 489-497, 2012.

[16] A. T. Peana, A. R. Assaretti, G. Muggironi, P. Enrico, and M. Diana, "Reduction of ethanol-derived acetaldehyde induced motivational properties by L-cysteine," Alcoholism Clinical and Experimental Research, vol. 33, no. 1, pp. 43-48, 2009.

[17] K. Yamashita, M. Noguchi, A. Mizukoshi, and Y. Yanagisawa, "Acetaldehyde removal from indoor air through chemical absorption using L-cysteine," International Journal of
Environmental Research and Public Health, vol. 7, no. 9, pp. 3489-3498, 2010.

[18] C. Luo and X. Zhang, "Elimination of acetaldehyde and antioxidation of A549 intracellular environment by L-cysteine," Food Science, vol. 34, pp. 247-250, 2013.

[19] P. D. Ray, B. W. Huang, and Y. Tsuji, "Reactive oxygen species (ROS) homeostasis and redox regulation in cellular signaling," Cellular Signalling, vol. 24, no. 5, pp. 981-990, 2012.

[20] S. Nakajima and M. Kitamura, "Bidirectional regulation of NF- $\kappa$ B by reactive oxygen species: a role of unfolded protein response," Free Radical Biology and Medicine, vol. 65, pp. 162-174, 2013.

[21] M. L. Circu and T. Y. Aw, "Reactive oxygen species, cellular redox systems, and apoptosis," Free Radical Biology and Medicine, vol. 48, no. 6, pp. 749-762, 2010.

[22] M. Filosto, M. Scarpelli, M. S. Cotelli et al., "The role of mitochondria in neurodegenerative diseases," Journal of Neurology, vol. 258, no. 10, pp. 1763-1774, 2011.

[23] A. J. Kowaltowski, R. F. Castilho, and A. E. Vercesi, "Mitochondria and reactive oxygen species," Free Radical Biology and Medicine, vol. 15, no. 4, pp. 333-343, 2009.

[24] P. Caroppi, F. Sinibaldi, L. Fiorucci, and R. Santucci, “Apoptosis and human diseases mitochondrion damage and lethal role of released cytochrome $c$ as proapoptotic protein," Current Medicinal Chemistry, vol. 16, no. 31, pp. 4058-4065, 2009.

[25] H. Sprince, C. M. Parker, G. G. Smith, and L. J. Gonzales, "Protection against acetaldehyde toxicity in the rat by L-cysteine, thiamin and L-2-methylthiazolidine-4-carboxylic acid," Agents Actions, vol. 4, no. 2, pp. 125-130, 1974.

[26] B. E. Farfán Labonne, M. Gutiérrez, L. E Gómez-Quiroz et al., "Acetaldehyde-induced mitochondrial dysfunction sensitizes hepatocytes to oxidative damage," Cell Biology and Toxicology, vol. 25, no. 6, pp. 599-609, 2009.

[27] T. Uemura, Y. Tanaka, K. Higashi et al., "Acetaldehydeinduced cytotoxicity involves induction of spermine oxidase at the transcriptional level," Toxicology, vol. 310, pp. 1-7, 2013.

[28] J. B. Hoek and J. G. Pastorino, "Ethanol, oxidative stress, and cytokine-induced liver cell injury," Alcohol, vol. 27, no. 1, pp. 63-68, 2002.

[29] M. C. Gutierrez-Ruiz, L. E. Gomez Quiroz, E. Hernandez et al., "Cytokine response and oxidative stress produced by ethanol, acetaldehyde and endotoxin treatment in HepG2 cells," Israel Medical Association Journal, vol. 3, no. 2, pp. 131-136, 2001.

[30] W. Y. Chen, J. Zhang, S. Ghare, S. Barve, C. Mcclain, and S. Joshibarve, "Acrolein is a pathogenic mediator of alcoholic liver disease and the scavenger hydralazine is protective in mice," Cellular and Molecular Gastroenterology and Hepatology, vol. 2, no. 5, pp. 685-700, 2016. 


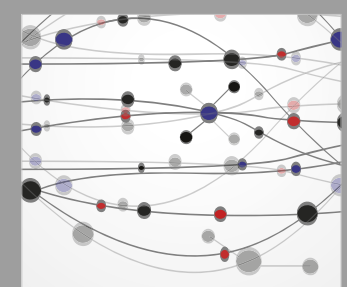

The Scientific World Journal
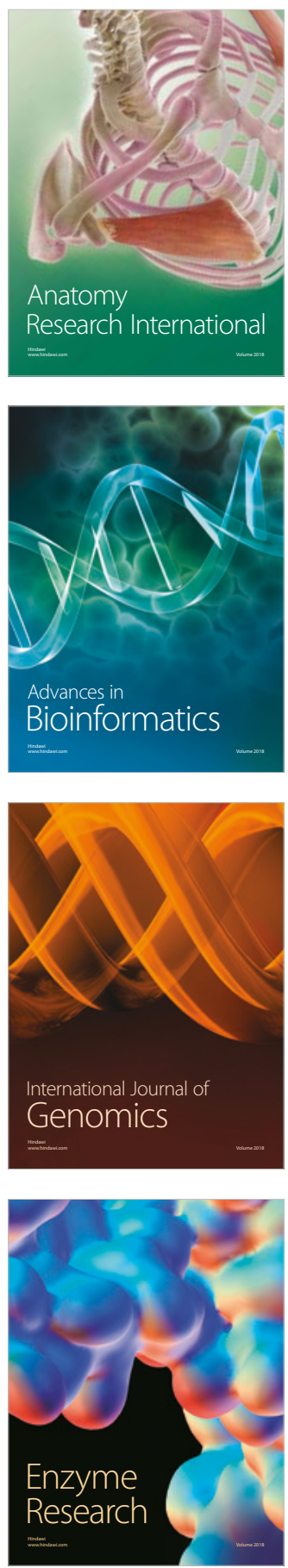
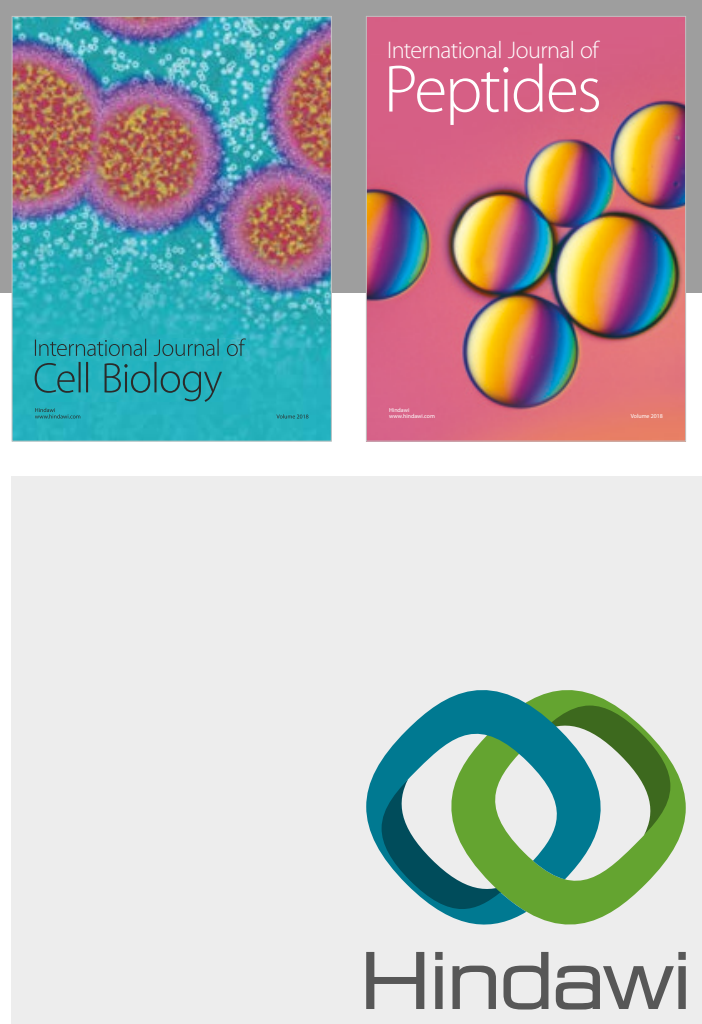

Submit your manuscripts at

www.hindawi.com
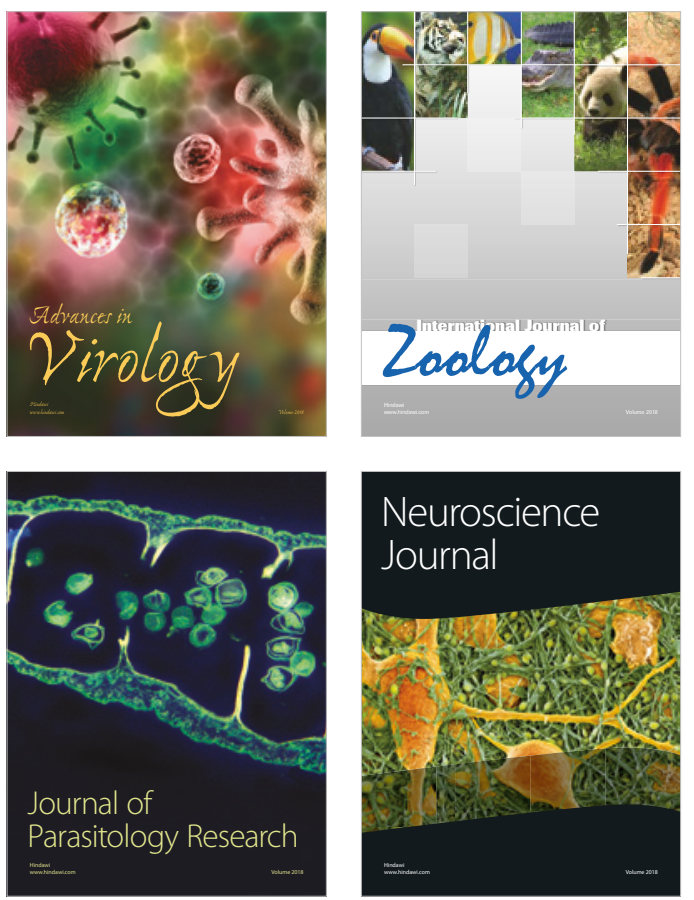
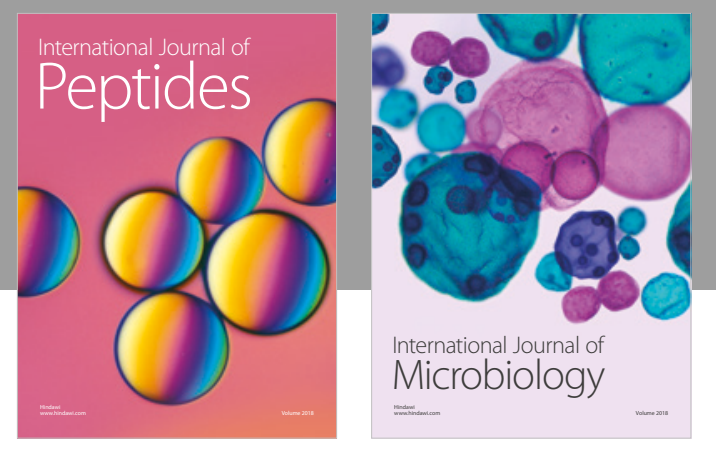

nternational Journal of Microbiology
Journal of
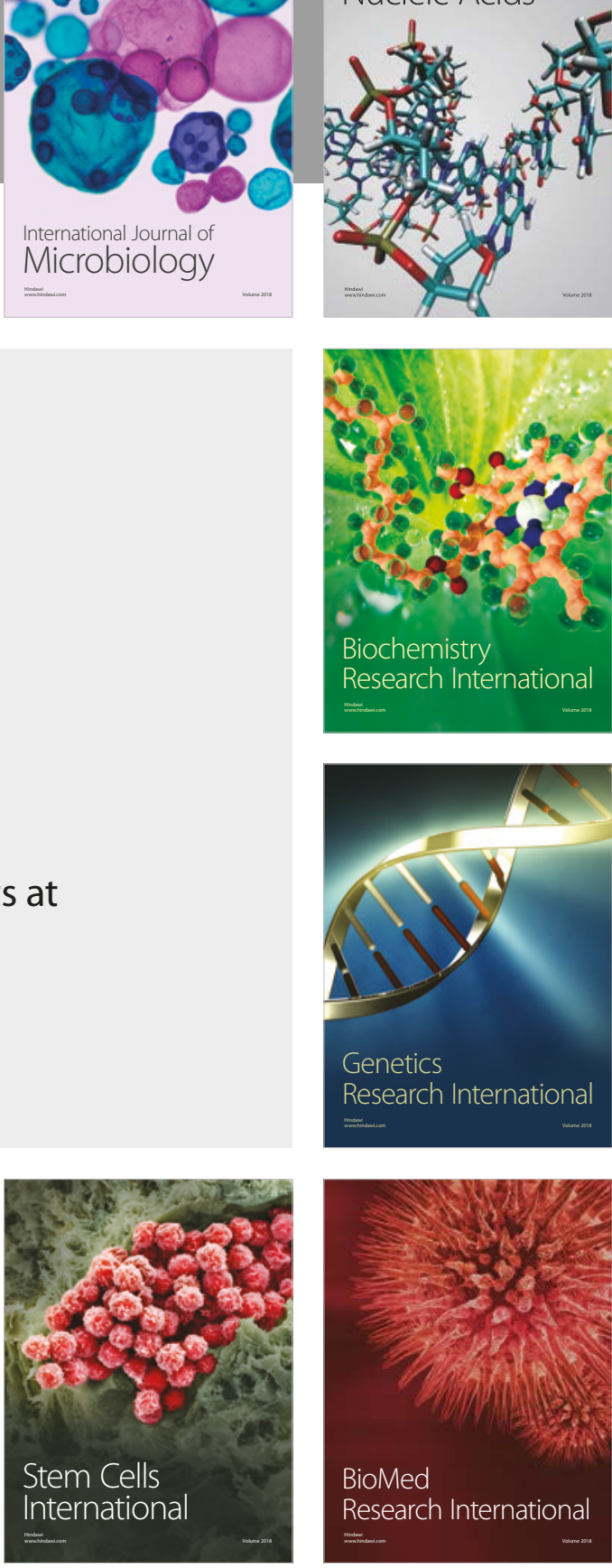
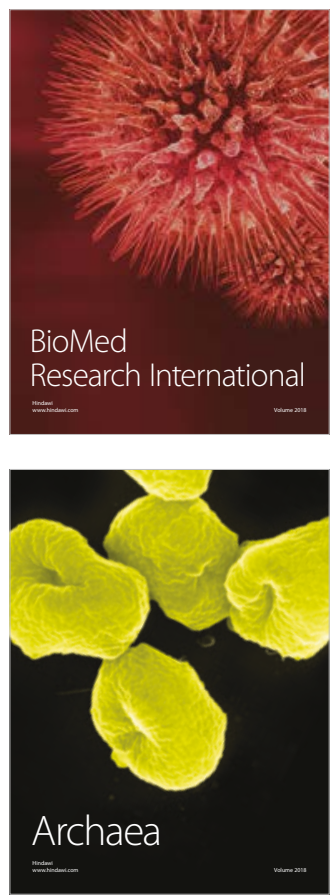